\title{
Dispersions of Metal Oxides in the Presence of Anionic Surfactants
}

\author{
Leszek Ruchomski, Edward Mączka and Marek Kosmulski *iD \\ Lublin University of Technology, Laboratory of Electrochemistry, Nadbystrzycka 38, 20-618 Lublin, Poland; \\ l.ruchomski@pollub.pl (L.R.); e.maczka@pollub.pl (E.M.) \\ * Correspondence: m.kosmulski@pollub.pl; Tel.: +48-81-5384355
}

Received: 22 November 2018; Accepted: 20 December 2018; Published: 21 December 2018

\begin{abstract}
We studied the behavior of dilute dispersions of nanoparticles of hematite, alumina, and titania in the presence of various concentrations of very pure sodium dodecyl-, tetradecyl-, and hexadecylsulfate. The concentrations studied were up to critical micelle concentration (CMC) for sodium dodecylsulfate, and up to the solubility limit in case of sodium tetradecyl- and hexadecylsulfate. The dispersions were adjusted to different $\mathrm{pH}(3-11)$, and $10^{-3} \mathrm{M} \mathrm{NaCl}$ was used as the supporting electrolyte. The solid-to-liquid ratio was strictly controlled in all dispersions, and the behavior of fresh dispersions was compared with dispersions aged for up to eight days. The presence of very low concentrations of ionic surfactants had rather insignificant effects on the $\zeta$ potentials of the particles. At sufficient concentrations of ionic surfactants the isoelectric point (IEP) of metal oxides shifted to low $\mathrm{pH}$, and the long-chain surfactants were more efficient in shifting the IEP than their shorter-chain analogues. Once the surfactant concentration reached a critical value, the $\zeta$ potentials of the particles reached a $\mathrm{pH}$-independent negative value, which did not change on further increase in the surfactant concentration and/or aging of the dispersion. This critical concentration increases with the solid-to-liquid ratio, and it is rather consistent (for certain oxides and certain surfactants) when it is expressed as the amount of surfactant per unit of surface area. Surprisingly, the surfactant-stabilized dispersions always showed a substantial degree of aggregation; that is, the particle size observed in dispersions by dynamic light scattering was higher than the size of particles observed in dry powders by electron microscopy. Apparently, in spite of relatively high $\zeta$ potentials (about $60 \mathrm{mV}$ in absolute value), the surfactant-stabilized dispersions consist of aggregates rather than of primary particles, and in certain dispersions the high concentration of surfactant seems to induce aggregation rather than prevent it.
\end{abstract}

Keywords: zeta potential; particle size; titania; hematite; alumina

\section{Introduction}

Dispersions of metal oxides containing sodium dodecylsulfate (SDS) have been extensively studied by different methods [1-20]. The specific adsorption of dodecylsulfate anions results in a reversal of the sign of the $\zeta$ potential of metal oxide particles from positive to negative in the acidic range. The electrokinetic curves obtained in the presence of SDS often show a maximum near the pristine isoelectric point (IEP) of metal oxide. In this respect, dodecylsulfate is different from most other anions, which cause a shift in the IEP of metal oxide to low $\mathrm{pH}$, but the electrokinetic curves do not show a maximum. The reasons for nonstandard behavior of SDS have been discussed in detail elsewhere [20]. The other unusual property of dispersions of metal oxides containing SDS is a high degree of aggregation of particles in spite of high absolute values of the $\zeta$ potential. In this study, we focus on the aggregation behavior. On top of dispersions of metal oxides containing SDS, we also studied dispersions stabilized with sodium tetradecyl- and hexadecylsulfate, that is, long 
chained analogs of SDS. Many studies of aggregation reported in the literature were carried out after one arbitrarily selected aging time (ranging from a few minutes to several weeks), and many other studies were carried out after several different aging times in order to check if the aggregation degree was time-dependent [1]. Several studies report a stable behavior in time, and in several other studies the degree of aggregation was time-dependent. In this present study, we compared the behavior of fresh and aged dispersions.

Multiple publications report a stability ratio in dispersions as a function of the concentration of coagulation agent [1]. Different amounts of coagulation agent are added (in the form of a concentrated solution) to an originally stable dispersion, and a quantity related to coagulation, e.g., turbidity of dispersion, is followed as a function of time. This approach is not applicable to our study because we use a low and constant concentration of $\mathrm{NaCl}$ (which can induce coagulation, but at higher concentrations), and the anionic surfactants used in the present study show limited solubility in water (the final concentrations of sodium tetradecyl- and hexadecylsulfate are close to saturation).

\section{Materials and Methods}

Sodium dodecylsulfate for biochemistry (99\%) was acquired from Acros (Geel, Belgium), sodium tetradecylsulfate from Aldrich (Darmstadt, Germany) (99\%), and sodium hexadecylsulfate from Alfa Aesar (Karlsruhe, Germany) (99\%). Hematite was synthesized by heating an acidified $0.02 \mathrm{M} \mathrm{FeCl}_{3}$ solution at $100{ }^{\circ} \mathrm{C}$ for $1 \mathrm{~d}$, according to the classical recipe by Matijević [21]. The powder was removed from solution by centrifugation, washed with water, and freeze-dried. Its specific surface area (determined by means of BET method, Gemini V, Micromeritics, Norcross, USA) was $26 \mathrm{~m}^{2} / \mathrm{g}$, the particle diameter determined via TEM (transmission electron microscopy) was $50 \mathrm{~nm}$, and the pristine IEP was at $\mathrm{pH} 9$. Alu C alumina $\left(100 \mathrm{~m}^{2} / \mathrm{g}, 20 \mathrm{~nm}, \mathrm{pH} 9\right)$ and $\mathrm{P} 25$ titania $\left(50 \mathrm{~m}^{2} / \mathrm{g}, 30 \mathrm{~nm}\right.$, $\mathrm{pH} 6.5$, respectively) were acquired from Degussa-Evonik. All commercial chemicals were used as obtained. The dispersions of the powders (1:10,000 by mass) in $10^{-3} \mathrm{M} \mathrm{NaCl}$ were prepared and stored in plastic test-tubes to avoid contact with glass. Storage of dispersions of metal oxides in glass is well known to induce a shift in their IEP to low $\mathrm{pH}$ due to specific adsorption of silicate anions. The $\mathrm{pH}$ was adjusted with $\mathrm{NaOH}$ or $\mathrm{HCl}$ solutions, and measured just before the electrokinetic measurement. The electrophoretic mobility and particle size were measured by means of a Malvern ZetaSizer Nano $\mathrm{ZS}$ at $25^{\circ} \mathrm{C}$. Two series of measurements were performed: directly after preparation of the dispersion, and after aging the dispersion for a few days (cf. Table S1).

\section{Results and Discussion}

The electrokinetic behavior of metal oxides in fresh dispersions containing different amounts of anionic surfactants was presented and discussed in detail in our previous paper [20]. In Figures 1-8, we show the electrokinetic curves in dispersions aged from one to eight days. 


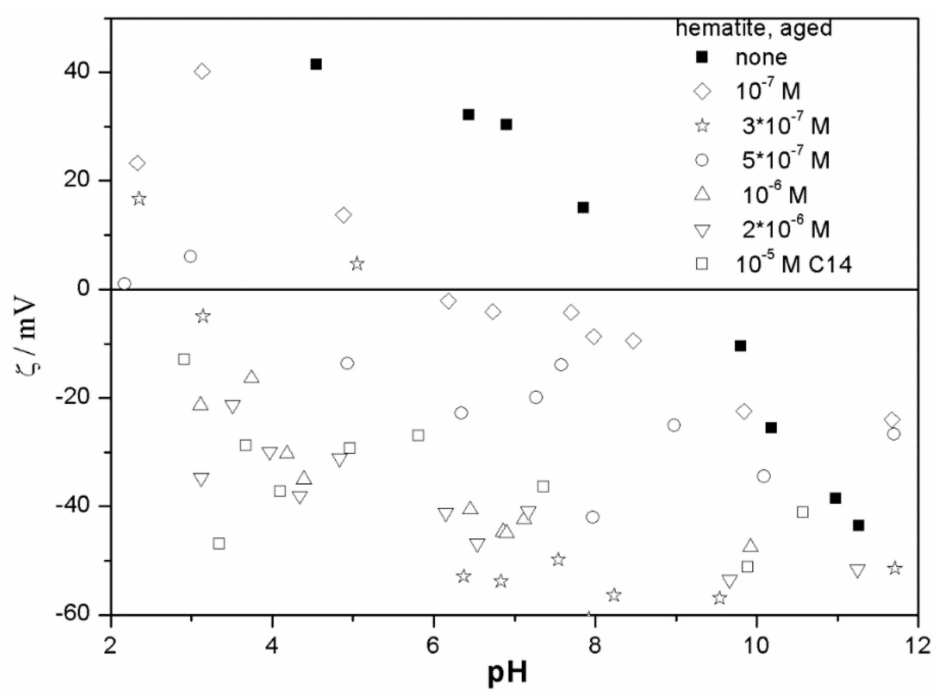

Figure 1. The $\zeta$ potential of hematite in aged dispersions in the presence of sodium tetradecylsulfate.

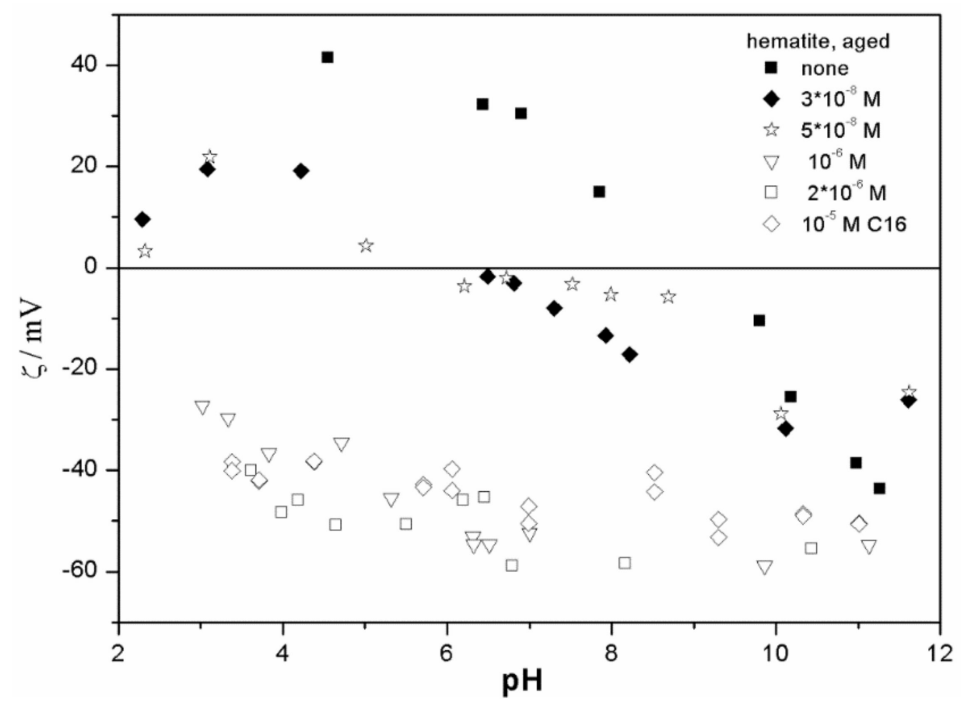

Figure 2. The $\zeta$ potential of hematite in aged dispersions in the presence of sodium hexadecylsulfate.

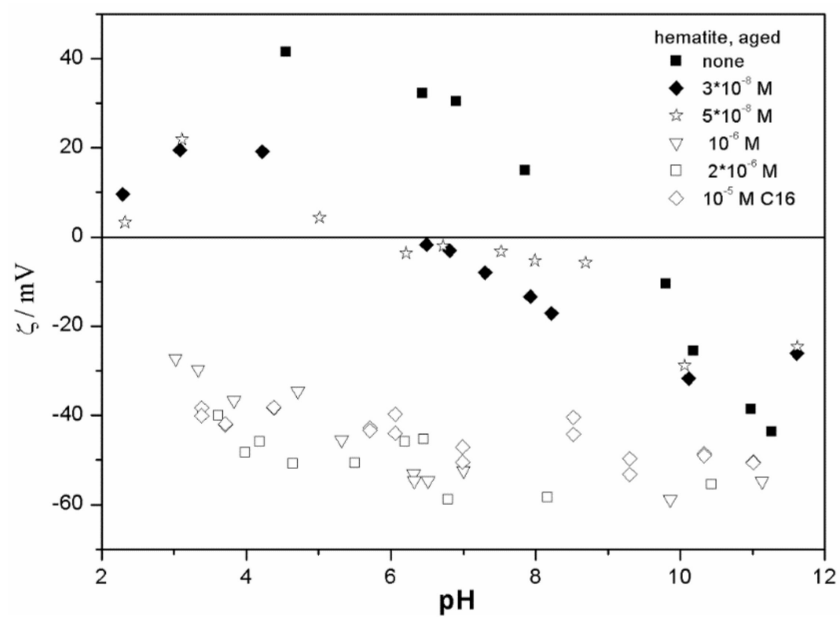

Figure 3. The $\zeta$ potential of titania in aged dispersions in the presence of sodium dodecylsulfate. 


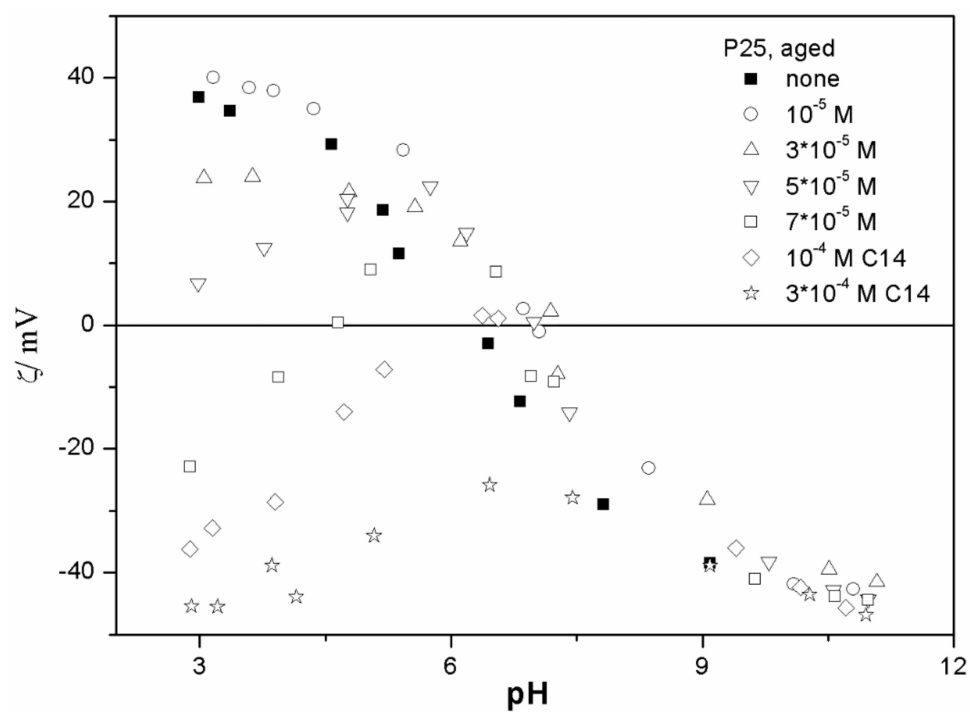

Figure 4. The $\zeta$ potential of titania in aged dispersions in the presence of sodium tetradecylsulfate.

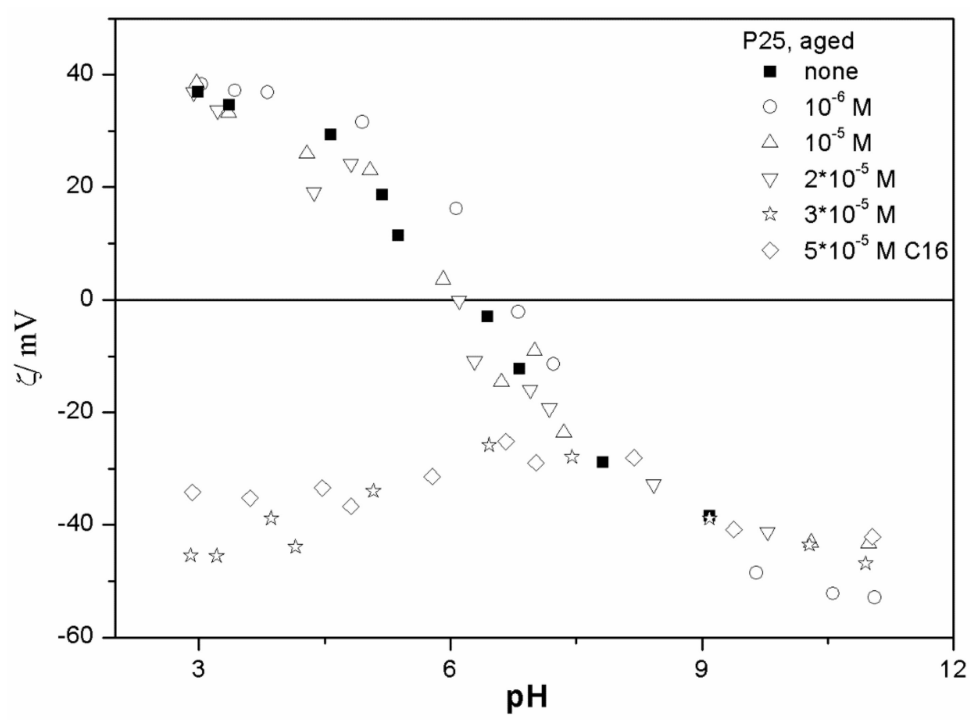

Figure 5. The $\zeta$ potential of titania in aged dispersions in the presence of sodium hexadecylsulfate.

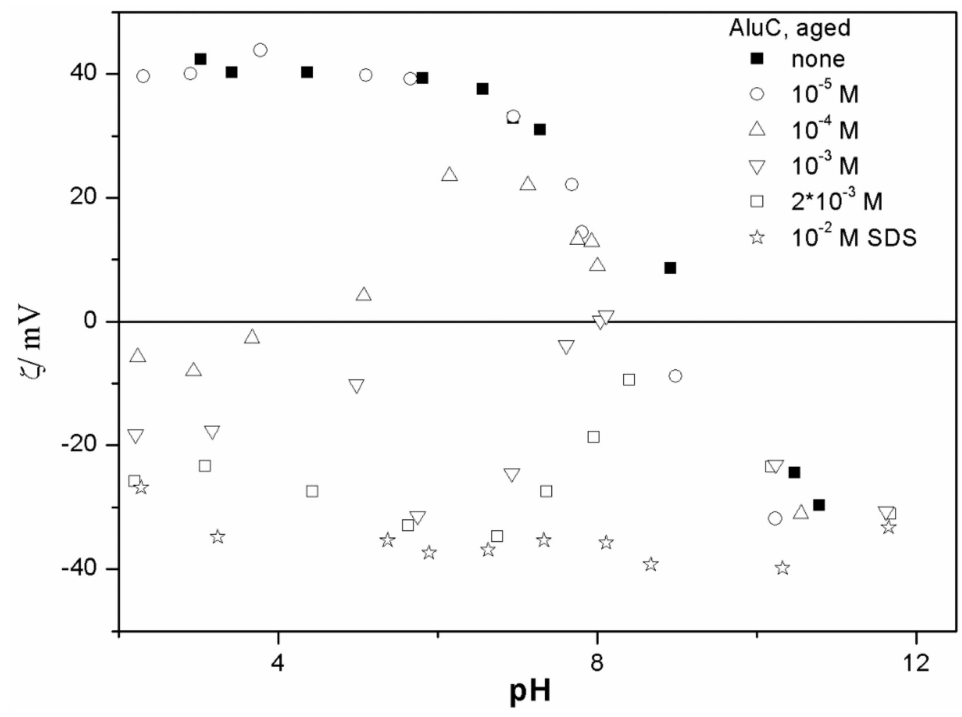

Figure 6. The $\zeta$ potential of alumina in aged dispersions in the presence of sodium dodecylsulfate. 


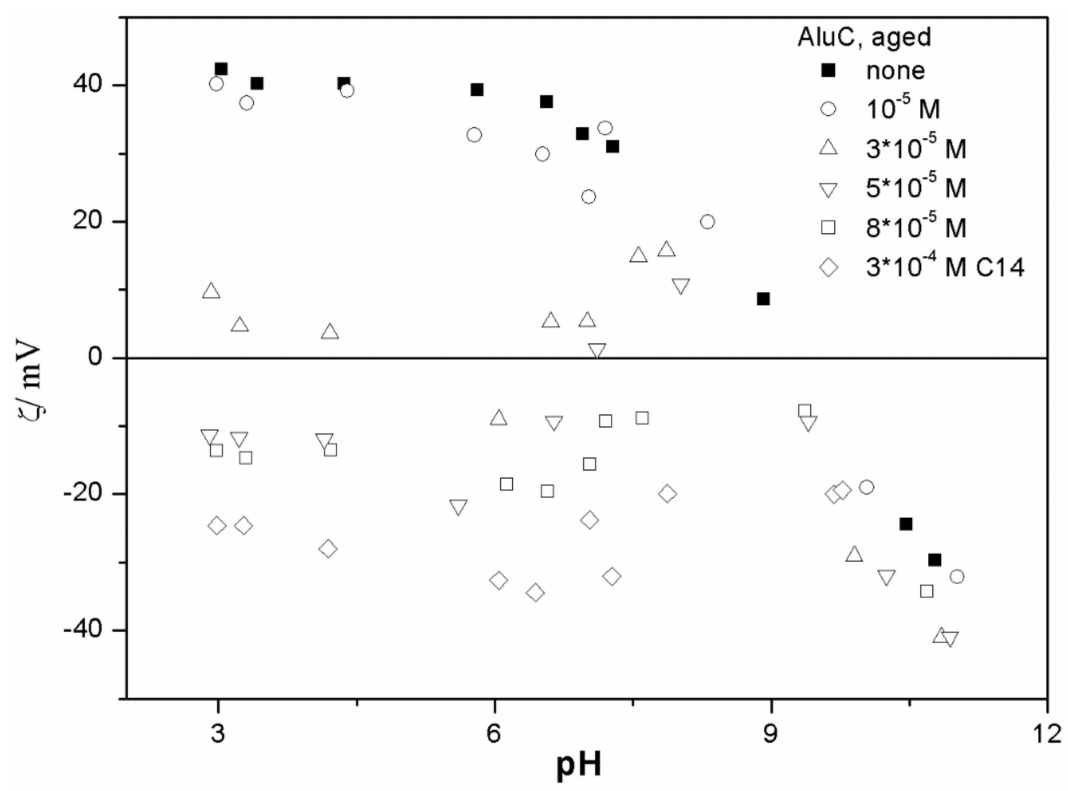

Figure 7. The $\zeta$ potential of alumina in aged dispersions in the presence of sodium tetradecylsulfate.

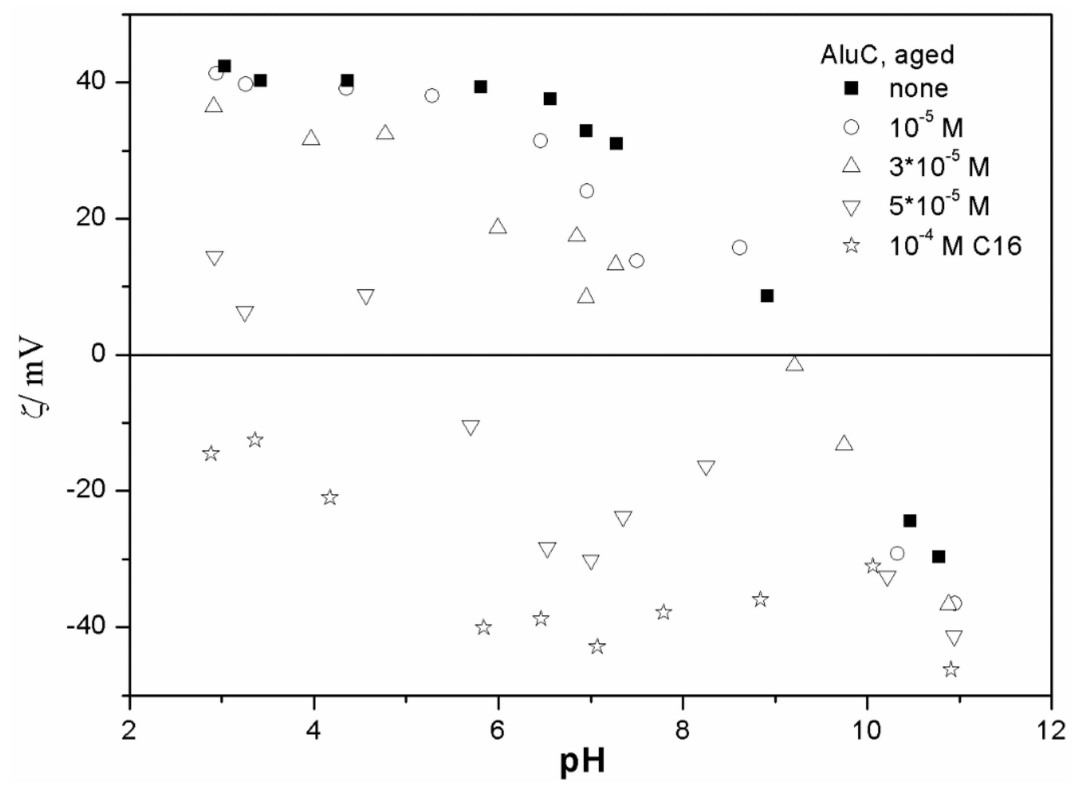

Figure 8. The $\zeta$ potential of alumina in aged dispersions in the presence of sodium hexadecylsulfate.

The $\zeta$ potentials shown in Figures 1-8 are very similar to the results reported for fresh dispersions [20]; that is, aging has rather insignificant effect on the $\zeta$ potentials of metal oxides in the presence of alkylsulfates. Two types of electrokinetic behavior have been observed. In dispersions containing SDS (Figures 3 and 6), and in titania- tetradecylsulfate (Figure 4) and alumina- tetradecylsulfate (Figure 7) systems, the specific adsorption of anionic surfactants resulted in a reversal of the sign of the $\zeta$ potential of metal oxide from positive to negative in the acidic range, but a rather insignificant effect in $\mathrm{pH}$-neutral range. Thus, the electrokinetic curves showed a clear maximum. In contrast, in dispersions containing sodium hexadecylsulfate, the presence of the surfactant resulted in a shift in the IEP to low $\mathrm{pH}$ (no clear maximum in the electrokinetic curves), which is a typical behavior observed in most anions other than SDS, and discussed in the introduction. The unusual electrokinetic behavior observed in the presence of SDS was interpreted in terms of surfactant adsorption in aggregated form (admicelles, hemimicelles) [20]. It should be emphasized that the $\zeta$ potentials shown in Figure 1-8 are only valid for certain solid-to-liquid ratios (here 1:10,000). 
With higher solid-to-liquid ratio, higher concentrations of surfactants are required to induce the same effect on the $\zeta$ potential. The sets of electrokinetic curves obtained at various solid-to-liquid ratios can be normalized in terms of concentration of surfactant per unit of surface area [2].

The anticorrelation between the absolute value of the $\zeta$ potential and the particle size has been widely discussed in the literature, and the maximum in the particle size as the function of $\mathrm{pH}$ has been considered as a method of determination of the IEP. Indeed, many studies indicate a correlation between the pristine IEP of metal oxides and the $\mathrm{pH}$ of the maximum in the particle size [1]. The literature is full of reports on the aggregation of the materials studied in this paper (especially P25 and AluC) in dilute 1-1 electrolytes in the absence of ionic surfactants, including several publications by the present authors. While the correlation between the maximum in the particle size and IEP is commonplace, in most studies, primary particles were not observed, but a certain degree of aggregation was detected even far from IEP, and with absolute values of $\zeta$ potentials higher than $50 \mathrm{mV}$.

The fresh and aged dispersions were turbid, but they were not homogeneous. The particles were deposited on the walls of plastic vials, and sediment was visible on their bottoms.

The relationship between the absolute value of the $\zeta$ potential and the particle size in fresh and aged dispersions of metal oxides containing anionic surfactants is illustrated in Figures 9-16. The same results in $\mathrm{pH}$-size coordinates are presented in Table S2. We only present a few selected results (a few concentrations of the surfactants), and the other (unpublished) results follow the trends presented and discussed below. The average particle size produced by Malvern Zetasizer is calculated according to certain model, and it does not reflect the actual size of the aggregates, especially when their shape is far from spherical. Nevertheless, the high values of average particle size reflect a high degree of aggregation of primary particles, and they are on the same order of magnitude as the size of the actual aggregates. The Malvern Zetasizer also produces the degree of polydispersity, which is not reported here, and which was high in most specimens (typically about 0.5 and $>0.2$ in most specimens), and best-fit uni-, bi-, or trimodal distributions of particle size. Many authors report such graphs in their publications, but these distributions reflect the best-fit model parameters rather than the actual distributions, and their relevance to the actual dispersions is limited.

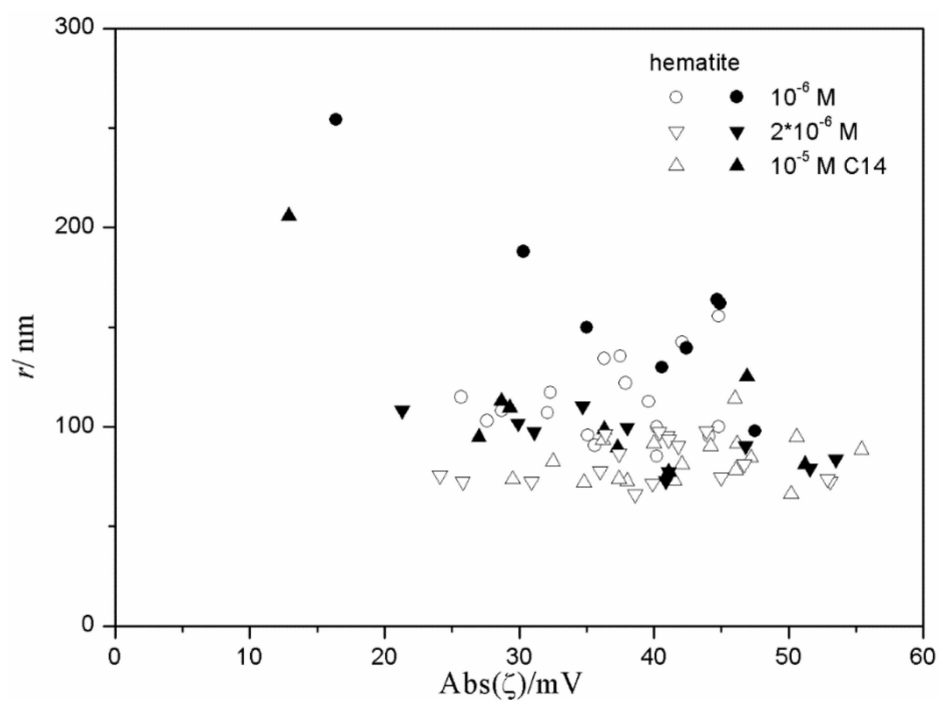

Figure 9. The particle size as a function of $|\zeta|$ in fresh (white points) and aged (black points) dispersions of hematite in the presence of sodium tetradecylsulfate. 


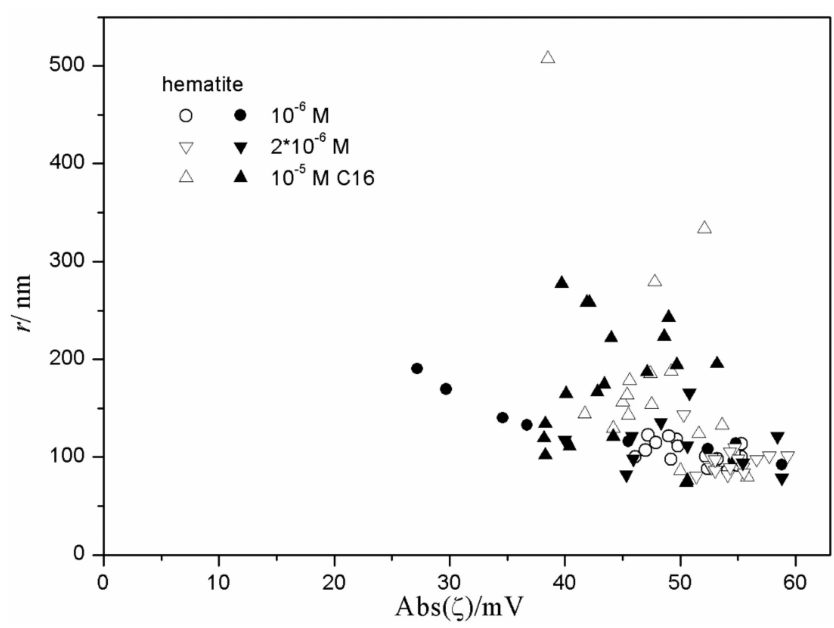

Figure 10. The particle size as a function of $|\zeta|$ in fresh (white points) and aged (black points) dispersions of hematite in the presence of sodium hexadecylsulfate.

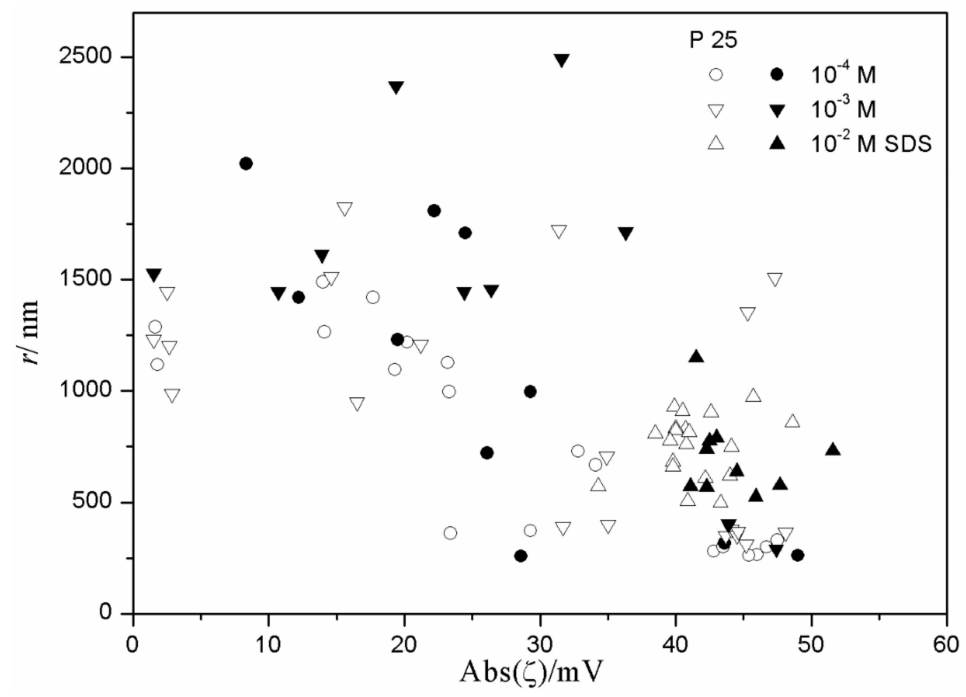

Figure 11. The particle size as a function of $|\zeta|$ in fresh (white points) and aged (black points) dispersions of titania in the presence of sodium dodecylsulfate.

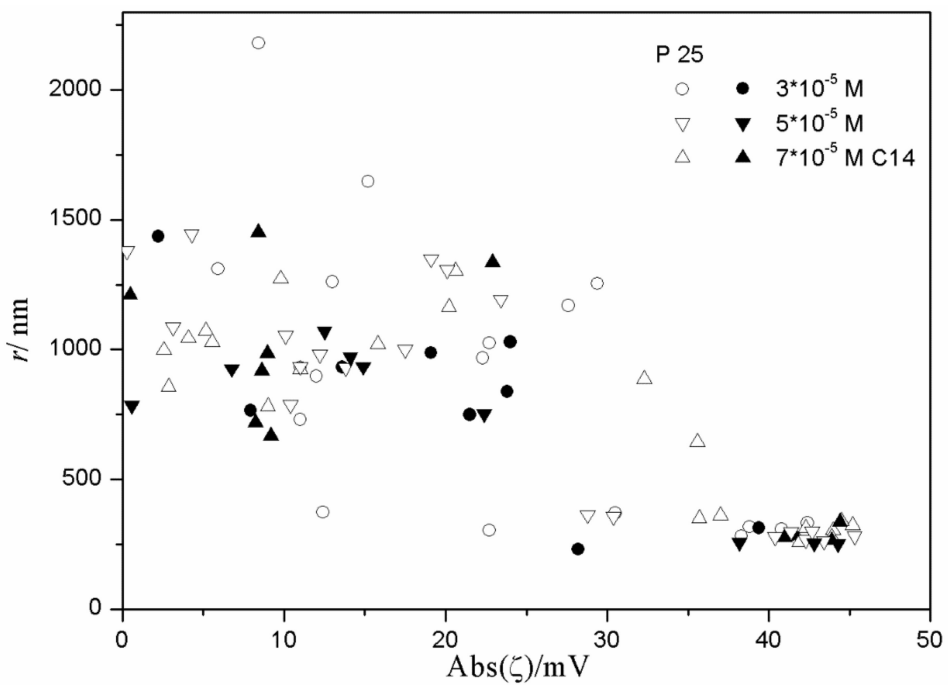

Figure 12. The particle size as a function of $|\zeta|$ in fresh (white points) and aged (black points) dispersions of titania in the presence of sodium tetradecylsulfate. 


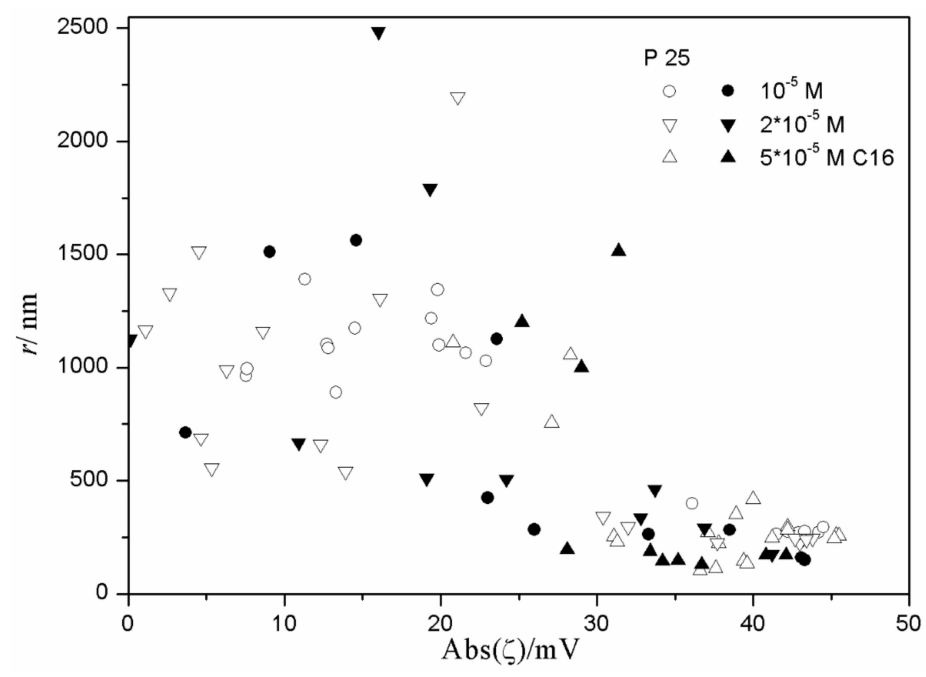

Figure 13. The particle size as a function of $|\zeta|$ in fresh (white points) and aged (black points) dispersions of titania in the presence of sodium hexadecylsulfate.

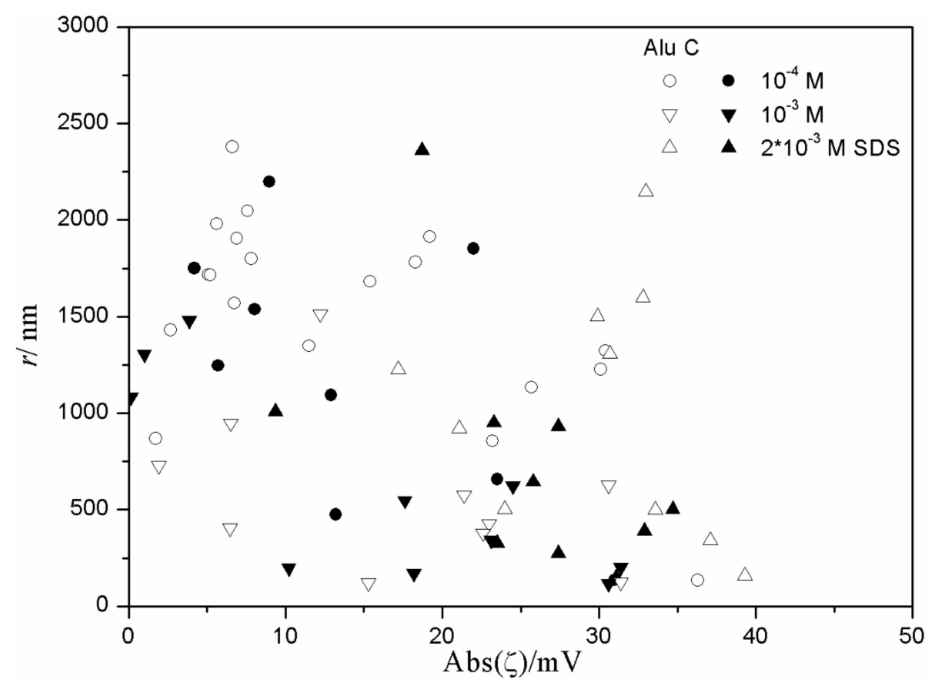

Figure 14. The particle size as a function of $|\zeta|$ in fresh (white points) and aged (black points) dispersions of alumina in the presence of sodium dodecylsulfate.

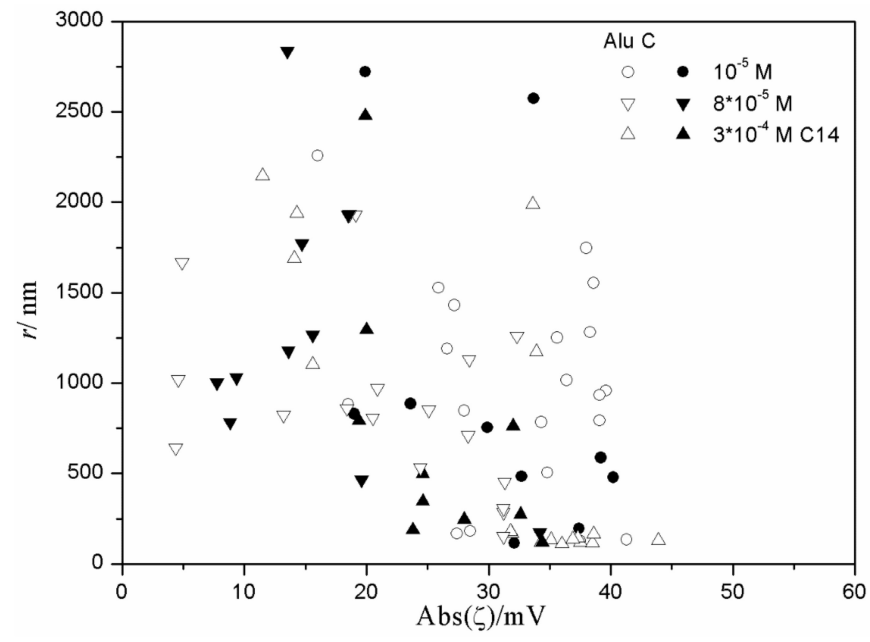

Figure 15. The particle size as a function of $|\zeta|$ in fresh (white points) and aged (black points) dispersions of alumina in the presence of sodium tetradecylsulfate. 


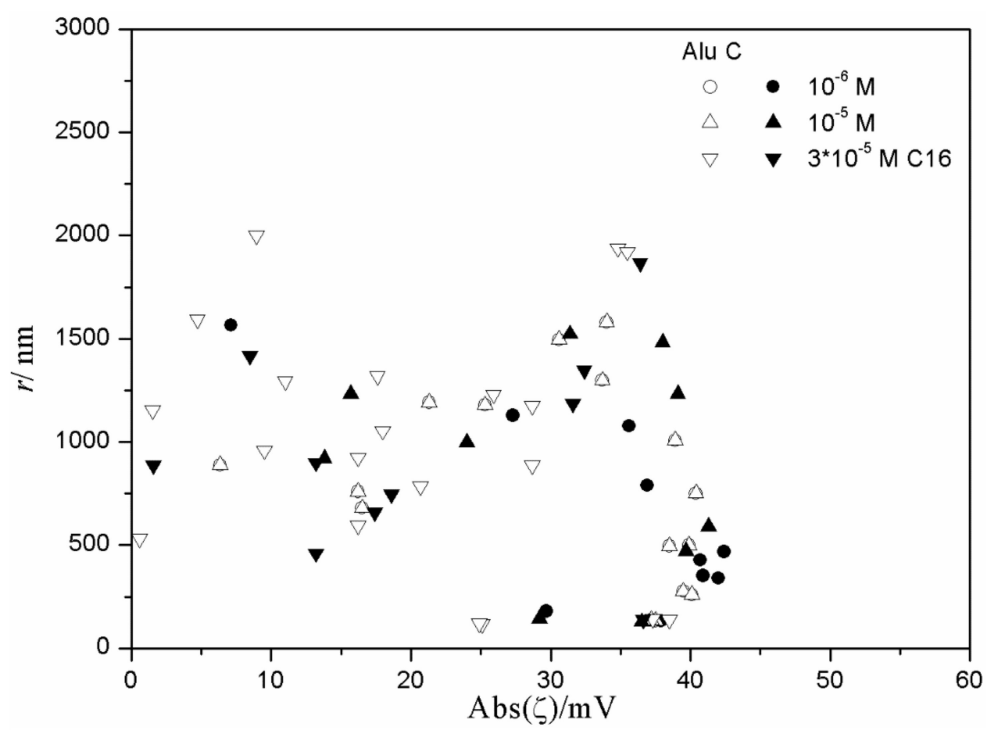

Figure 16. The particle size as a function of $|\zeta|$ in fresh (white points) and aged (black points) dispersions of alumina in the presence of sodium hexadecylsulfate.

In many papers, including our publications $[17,22]$, the results of electrophoretic measurements are presented as electrophoretic mobility vs. $\mathrm{pH}$ rather than as $\zeta$ vs. $\mathrm{pH}$ curves. Both approaches have their pros and cons. With irregularly-shaped and flexible aggregates and $1<\kappa a<100$, exact calculation of $\zeta$ from electrophoretic mobility is not possible, and the $\zeta$ potential can only be estimated [1], while the electrophoretic mobility is an exact experimental result. In this present paper, we show $\zeta$ rather than mobility in the figures, although we do realize that our $\zeta$ is only an approximation. Our approach has the following advantages:

- Our $\zeta$ can be directly compared with experimental results from other publications, including the results obtained by electroosmosis and electroacoustic methods.

- Our $\zeta$ can be directly compared with the results of model calculations.

- Our $\zeta$ can be directly used in calculations, e.g., of interaction curves in the DLVO (Derjaguin-Landau-Verwey-Overbeek) theory.

The electrophoretic mobilities corresponding to the data points from Figures 1-16 are presented in Table S3. They can also be calculated from the data presented in the figures by the division of $\zeta$ (expressed in $\mathrm{mV}$ ) by 12.8 , and the resulting mobility is expressed in $10^{-8} \mathrm{~m}^{2} / \mathrm{V} / \mathrm{s}$.

Figures 9-16 indicate a substantial degree of aggregation of the particles even at relatively high absolute values of the $\zeta$ potential. In dispersions of hematite, the lowest observed average radii were about $70 \mathrm{~nm}$, while the radii from TEM (transmission electron microscopy) were about $25 \mathrm{~nm}$. In dispersions of titania, the lowest observed average radii were about $100 \mathrm{~nm}$, while the radii from TEM were about $15 \mathrm{~nm}$. In dispersions of alumina, the lowest observed average radii were about $110 \mathrm{~nm}$, while the radii from TEM were about $10 \mathrm{~nm}$.

Figures 9 and 10 show very weak correlation between the absolute value of $\zeta$ potential and the particle size of hematite. Interestingly enough, the highest degree of aggregation (particle radii of 200-500 nm) was only observed in the presence of $10^{-5} \mathrm{M}$ hexadecylsulfate, in fresh and aged dispersions, while at lower concentrations of hexadecylsulfate the particles were smaller. This may suggest that a high concentration of hexadecylsulfate induces particle aggregation. However, several dispersions containing $10^{-5} \mathrm{M}$ hexadecylsulfate showed low degree of aggregation (particle radii $<100 \mathrm{~nm}$ ). Almost all data points shown in Figures 9 and 10 refer to a relatively high absolute value of $\zeta$ potential $(>25 \mathrm{mV})$, and two data points corresponding to low absolute value of $\zeta$ potential show a substantial degree of aggregation. 
Figures 11-13 show anticorrelation between the absolute value of $\zeta$ potential and the particle size of titania, especially in dispersions stabilized with tetradecyl- and hexadecylsulfate. Relatively low degrees of aggregation (particle radii $<250 \mathrm{~nm}$ ) are only observed at absolute values of $\zeta$ potential $>30 \mathrm{mV}$, while for absolute values of $\zeta$ potential $<30 \mathrm{mV}$ the particle radii are $>500 \mathrm{~nm}$, with a few exceptions. There is no systematic effect on aging on the particle size. The results obtained in the presence of $10^{-3}$ and $10^{-2} \mathrm{M}$ SDS (Figure 11) are exceptional; in spite of high absolute value of $\zeta$ potential $(>40 \mathrm{mV})$, most dispersions show substantial aggregation (particle radii $>500 \mathrm{~nm}$ ). Such an aggregation was not observed in dispersions stabilized with tetradecyl- or hexadecylsulfate or in $10^{-4} \mathrm{M}$ SDS. This may suggest that a high concentration of SDS induces particle aggregation.

The results shown in Figure 14 for the alumina-SDS system indicate a random scatter rather than any correlation between the absolute value of $\zeta$ potential and the particle size. The only correlation is that in dispersions with very low absolute value of $\zeta$ potential $(<10 \mathrm{mV})$ the degree of aggregation is always high (particle radii $>400 \mathrm{~nm}$ ). In alumina dispersions stabilized with tetradecyl- and hexadecylsulfate (Figures 15 and 16), low degrees of aggregation (particle radii $<200 \mathrm{~nm}$ ) are only observed at high absolute values of $\zeta$ potential $(>25 \mathrm{mV})$, but in many systems with high absolute values of $\zeta$ potential $(>25 \mathrm{mV})$, the degree of aggregation was very high.

In spite of the similarity in surface-charging behaviors of different metal oxides, which is often emphasized in the literature [1], the electrokinetic and aggregation behaviors of hematite, titania, and alumina found in this study showed substantial differences. The apparent $\zeta$ potentials of hematite showed the highest absolute values (up to $65 \mathrm{mV}$ ), the $\zeta$ potentials of titania showed absolute values up to $52 \mathrm{mV}$, and the $\zeta$ potentials of alumina showed absolute values up to $45 \mathrm{mV}$. These absolute values are probably underrated, because they were calculated from the Smoluchowski equation, that is $\kappa a>100$ was assumed. Unfortunately, there is no method to accurately calculate the $\zeta$ potentials at $1<\kappa a<100$ in dispersions of irregularly-shaped particles or aggregates, and we cannot use the radii of the primary particles (which are nearly spherical) in the calculations because of the substantial degree of aggregation indicated in Figures 9-16. High degrees of aggregation in dispersions of alumina and titania (apparent particle radii in excess of $1000 \mathrm{~nm}$ are commonplace) and lower degrees of aggregation in dispersions of hematite (typical apparent particle radii of $100 \mathrm{~nm}$ ) are in line with high absolute values of $\zeta$ potentials of hematite and lower absolute values of $\zeta$ potentials of alumina and titania. The electrokinetic curves shown in Figures 1-8 are rather smooth, and the data points showing the apparent particle radii are very scattered. This is because the relationship between electrophoretic mobility and $\zeta$ potential is relatively insensitive to the shape and orientation of the particles, especially in the range of the $\zeta$ potentials low in absolute value. In contrast, the calculated particle size is very sensitive to the model assumptions. The scatter in the apparent particle radii indicates that the model used in the calculations by the Malvern software is not suitable for the studied systems, especially when large and irregularly shaped aggregates are present. Yet the order of magnitude of the particle sizes shown in Figures 9-16 is relevant to the order of magnitude of the actual aggregates, as discussed in the experimental section.

The idea that adsorbed surfactant molecules can act as bridges between primary particles and induce their aggregation was coined in early papers by Colic and co-workers [4,11], and this argument was repeated in many other publications [17-20]. Moreover, the effective dielectric constant within the aggregate is lower than in bulk water (due to the presence of hydrocarbon chains), thus, the effective Hamaker constant of particles interacting through such a medium is higher than of the same particles interaction through water. Moreover, the electrokinetic measurements produce the $\zeta$ potential of aggregates actually present in dispersion rather than of primary particles. The alkylsulfate anions are not uniformly distributed within the aggregate, and the $\zeta$ potential of aggregates is not representative for primary particles. High concentration of surfactant in the external corona of the aggregate may result in high $\zeta$ potential of the aggregate and substantial electrostatic repulsion between the aggregates, but not between particular primary particles within the same aggregate. 


\section{Conclusions}

The particles of hematite, titania, and alumina are aggregated in dilute dispersions containing sodium docecyl-, tetradecyl-, and hexadecylsulfate. The aggregation is more pronounced when the $\zeta$ potential has a low absolute value $(<30 \mathrm{mV})$, but even when the $\zeta$ potential has a high absolute value $(>40 \mathrm{mV})$, the aggregation is substantial, especially in dispersions of titania and alumina. The aging of dispersions has rather insignificant effects on the $\zeta$ potential and on the degree of aggregation.

Supplementary Materials: The following are available online at http:/ /www.mdpi.com/2504-5377/3/1/3/s1. Table S1. The time of aging of dispersions. Table S2. The $\mathrm{pH}$ values corresponding to the data points in Figures $9-16$. Table S3. The electrophoretic mobilities $\left(\mu\right.$, in $\left.10^{-8} \mathrm{~m}^{2} / \mathrm{V} / \mathrm{s}\right)$ corresponding to the data points in Figures 1-16.

Author Contributions: Conceptualization, M.K.; methodology, M.K.; synthesis of particles, E.M.; electrokinetic measurements, L.R.; writing—original draft preparation, M.K., E.M., L.R.; writing—review and editing, M.K., E.M., L.R.

Funding: This research received no external funding.

Conflicts of Interest: The authors declare no conflict of interest.

\section{References}

1. Kosmulski, M. Chemical Properties of Material Surfaces; Marcel Dekker: New York, NY, USA, 2001.

2. Mączka, E.; Luetzenkirchen, J.; Kosmulski, M. The significance of the solid-to-liquid ratio in the electrokinetic studies of the effect of ionic surfactants on mineral oxides. J. Colloid Interface Sci. 2013, 393, 228-233. [CrossRef] [PubMed]

3. Bai, B.F.; Hankins, N.P.; Hey, M.J.; Kingman, S.W. In situ mechanistic study of SDS adsorption on hematite for optimized froth flotation. Ind. Eng. Chem. Res. 2004, 43, 5326-5338. [CrossRef]

4. Fuerstenau, D.W.; Colic, M. Self-association and reverse hemimicelle formation at solid - water interfaces in dilute surfactant solutions. Colloids Surf. A 1999, 146, 33-47. [CrossRef]

5. Yezek, L.; Rowell, R.L.; Holysz, L.; Chibowski, E. Adsorption of sodium dodecyl sulfate to colloidal titanium dioxide: An electrophoretic fingerprinting investigation. J. Colloid Interface Sci. 2000, 225, 227-232. [CrossRef] [PubMed]

6. Kobayashi, M.; Yuki, S.; Adachi, Y. Effect of anionic surfactants on the stability ratio and electrophoretic mobility of colloidal hematite particles. Colloids Surf. A 2016, 510, 190-197. [CrossRef]

7. Pham, T.D.; Kobayashi, M.; Adachi, Y. Adsorption of anionic surfactant sodium dodecyl sulfate onto alpha alumina with small surface area. Colloid Polym. Sci. 2015, 293, 217-227. [CrossRef]

8. Koopal, L.K.; Lee, E.M.; Bohmer, M.R. Adsoption of cationic and anionic surfactants on charged metal oxide surfaces. J. Colloid Interface Sci. 1995, 170, 85-97. [CrossRef]

9. Gao, X.; Chorover, J. Adsorption of sodium dodecyl sulfate (SDS) at ZnSe -Fe2O3 surfaces: Combining infrared spectroscopy and batch uptake studies. J. Colloid Interface Sci. 2010, 348, 167-176. [CrossRef] [PubMed]

10. Fuerstenau, D.W. Equilibrium and nonequilibrium phenomena associated with the adsorption of ionic surfactants at solid-water interfaces. J. Colloid Interface Sci. 2002, 256, 79-90. [CrossRef]

11. Colic, M.; Fuerstenau, D.W. Influence of the dielectric constant of the media on oxide stability in surfactant solutions. Langmuir 1997, 13, 6644-6649. [CrossRef]

12. Dobson, K.; Roddick-Lanzilotta, A.; McQuillan, A. An in situ infrared spectroscopic investigation of adsorption of sodium dodecylsulfate and of cetyltrimethylammonium bromide surfactants to $\mathrm{TiO}_{2}, \mathrm{ZrO}_{2}$, $\mathrm{Al}_{2} \mathrm{O}_{3}$, and $\mathrm{Ta}_{2} \mathrm{O}_{5}$ particle films from aqueous solutions. Vib. Spectrosc. 2000, 24, 287-295. [CrossRef]

13. Imae, T.; Muto, K.; Ikeda, S. The $\mathrm{pH}$ dependence of dispersion of $\mathrm{TiO}_{2}$ particles in aqueous surfactant solutions. Colloid Polym. Sci. 1991, 269, 43-48. [CrossRef]

14. Li, X.; Yoneda, M.; Shimada, Y.; Matsui, Y. Effect of surfactants on the aggregation and stability of TiO2 nanomaterial in environmental aqueous matrices. Sci. Total Env. 2017, 574, 176-182. [CrossRef] [PubMed]

15. Ji, Y.Q.; Black, L.; Koster, R.; Janek, M. Hydrophobic coagulation and aggregation of hematite particles with sodium dodecylsulfate. Colloids Surf. A 2007, 298, 235-244. [CrossRef] 
16. Yang, Y.J.; Kelkar, A.V.; Zhu, X.L.; Bai, G.R.; Hg, H.T.; Corti, D.S.; Franses, D.I. Effect of sodium dodecylsulfate monomers and micelles on the stability of aqueous dispersions of titanium dioxide pigment nanoparticles against agglomeration and sedimentation. J. Colloid Interface Sci. 2015, 450, 434-445. [CrossRef] [PubMed]

17. Kosmulski, M.; Maczka, E. The effect of sodium alkyl sulfates (C8-C16) on the electrokinetic properties of hematite. Colloids Surf. A 2016, 492, 152-159. [CrossRef]

18. Kosmulski, M.; Maczka, E.; Hartmann, J. Aggregation in dispersions of hematite and of hematite-akageneite composite containing anionic surfactants. J. Dispersion Sci. Technol. 2017, 38, 403-408. [CrossRef]

19. Maczzka, E.; Kosmulski, M. Time-dependent particle aggregation in SDS-hematite dispersions. Colloids Interface Sci. Comm. 2014, 1, 10-13.

20. Kosmulski, M.; Mączka, E.; Ruchomski, L. Two types of electrokinetic behavior of solid particles in the presence of anionic surfactants. J. Colloid Interface Sci. 2019, 533, 34-41. [CrossRef]

21. Matijević, E.; Scheiner, P. Ferric hydrous oxide sols 3. Preparation of uniform particles by hydrolysis of Fe(III)-chloride, Fe(III)-nitrate, and Fe(III)-perchlorate solutions. J. Colloid Interface Sci. 1978, 63, 509-524. [CrossRef]

22. Mączka, E.; Kosmulski, M. Hematite and hematite-akageneite composites. XRD and electrokinetic study and interaction with ionic surfactants. J. Colloid Interface Sci. 2015, 458, 130-135. [CrossRef] [PubMed]

(C) 2018 by the authors. Licensee MDPI, Basel, Switzerland. This article is an open access article distributed under the terms and conditions of the Creative Commons Attribution (CC BY) license (http:/ / creativecommons.org/licenses/by/4.0/). 